\title{
Experimental Study on MICP Technology for Strengthening Tail Sand under a Seepage Field
}

\author{
Zhi-jun Zhang $\mathbb{D}^{1,2}$ Biao Li, ${ }^{1,2}$ Lin Hu, ${ }^{1,2}$ Huai-miao Zheng, ${ }^{1,2}$ Gui-cheng He, ${ }^{1,2}$ Qing Yu, ${ }^{1,2}$ \\ and Ling-ling $\mathrm{Wu} \mathbb{1}^{1,2}$ \\ ${ }^{1}$ School of Resource \& Environment and Safety Engineering, University of South China, 421001 Hengyang, China \\ ${ }^{2}$ Hunan Province Engineering Technology Research Center for Disaster Prediction and Control on Mining Geotechnical Engineering, \\ 421001 Hengyang, China
}

Correspondence should be addressed to Ling-ling Wu; wllshmily@foxmail.com

Received 20 July 2020; Revised 7 September 2020; Accepted 4 October 2020; Published 24 October 2020

Academic Editor: Jinze Xu

Copyright ( 2020 Zhi-jun Zhang et al. This is an open access article distributed under the Creative Commons Attribution License, which permits unrestricted use, distribution, and reproduction in any medium, provided the original work is properly cited.

\begin{abstract}
Microbial-induced calcium carbonate precipitation (MICP) technology is a new green reinforcing technology in soil stabilization. Targeting on the problem that seepage is the main factor of causing the instability of a tailings dam, a comparative experiment is conducted, which includes the MICP technology on reinforcing tailings with or without the effect of a seepage field. The results of the comparative experiment are as follow: the mercury penetration test indicates that, under the function of a seepage field, the total pore in the tailing is relatively decreased; SEM shows that under the function of a seepage field, the intergranular pore increases; the direct shear test shows that under the function of a seepage field, the tailings' shear strength decreases; the determination of calcium ion content shows that the distribution of calcium carbonate in the tailings under the action of a seepage field is more uneven.
\end{abstract}

\section{Introduction}

The tailings dam is an artificial pollution source with high potential energy. Once the dam breaks, it will cause severe casualties, property damage, and environmental pollution [1]. Therefore, it has become an urgent issue in ensuring the safety and stability of the tailings dam in safe production. In addition, many of the tailings dam that put into use early in China have entered its middle or later stages. Those tailing dams are urgently needed to be strengthened to increase its stability, thereby ensuring a safe production. The current pile-up methods for a tailings dam include the upstream embankment method, centerline embankment method, downstream embankment method, dry pile-up method, and reservoir method. Above $90 \%$ of a tailings dam in China are upstream tailings dam, and the effect of seepage is one of the main factors that cause failures of an upstream tailings dam. The construction process of a tailing dam is also the production process of the mine enterprise. Therefore, the impact of seepage on the stability of the dam body has its particularity. The traditional dam body reinforcement technol- ogy adopts water glass, cement, and other chemical slurry materials, which not only has a high cost and large energy consumption but also causes permanent soil pollution and carbon dioxide emissions [2-4]. Therefore, researching a new tailings reinforcement technology with high efficiency, low cost, and environment protection, to improve the structure of the seepage field of the dam body, thereby ensuring the structure of the dam body, is one of the most urgent tasks of the mining industry in China.

Calcium carbonate is widely distributed in nature, it has relatively good durability, strength, and stable properties. Therefore, in recent years, the technology of using microbials to induce calcium carbonate precipitation to strengthen the soil has become a research hotspot. This biological reinforcement technology uses microbial cells and their biochemical activities to precipitate calcium carbonate crystals with good gelation from supersaturated calcium ion solutions, thereby increasing the risk of soil shear strength and erosion resistance, and thereby achieving the purpose of improving soil mechanics performance. Such microbial mineralization function is often called the microbial-induced calcite 
precipitation (MICP) technology [5]. Since Delft University of Technology firstly adopted MICP technology in onsite sandy soil stabilization in 2010 [6], such technology has become a research hotspot in various research fields [7-10]. However, it is almost blank in applying such technology in the special soil-like tailing sand. Applying this technology in managing the tailings dam has a great benefit in the economy, society, and environment. Since seepage is one of the main factors that could cause instability of the tailing dam body, while slip casting under the phreatic line has great significance in improving the safety and stability of the high tailings dam, the research compares the microbial grouting reinforcement experiment on the tailings sand with or without the effect of the seepage field. Through various detection methods of scanning electron microscopy, mercury intrusion experiment, shear experiment, and detection of calcium content in different parts, the changes of internal pores, gemel volume between particles, and shear strength are compared, and then, the macroimpact and microimpact of the seepage field on microbial grouting reinforcement are obtained. This has the significance of guiding the grouting reinforcement below the phreatic line of the tailings dam.

\section{Experiment Material and Equipment}

2.1. Tailings Sand. The tailings sand of this experiment is taken from the dry beach of a tailings pond in Hunan. According to the rules of geotechnical engineering test, it is measured that the tailings density on the original position is $2.043 \mathrm{~g} / \mathrm{cm}^{3}$, the nature moisture content is $12 \%$, the dry density is $1.826 \mathrm{~g} / \mathrm{cm}^{3}$, the void ratio is 0.466 , and the relative density is 2.85 . The nonuniform coefficient $C_{\mathrm{U}}<5$, and the coefficient of curvature $C_{C}>1$, which belongs to poorly graded soil. The particle size distribution curve is shown in Figure 1.

2.2. Bacteria Solution and Consolidating Fluid. In this experiment, Bacillus pastoris was selected as the dominant strain for cultivation, and it was purchased from the strain collection center (ATCC, 11859). After activation, it was put in the refrigerator at $4^{\circ} \mathrm{C}$. While using, the culture medium was introduced and it was placed on a shaker to shake and culture until $\mathrm{OD}_{600}$ of the bacterial solution is between 0.8 and 1.2. The composition of the culture medium is shown in Table 1 . Since urea can easily decompose at high temperatures, $0.45 \mu \mathrm{m}$ and $0.22 \mu \mathrm{m}$ microporous membranes are used for filtration and sterilization. Other ingredients are continuously sterilized by a high-temperature sterilizer at $121^{\circ} \mathrm{C}$ for 20 minutes. After sterilization, it is mixed with urea that is next to the alcohol lamp on the sterile table. The consolidating fluid is composed of $0.5 \mathrm{~mol} / \mathrm{L} \mathrm{CaCl}_{2}$ and urea solution.

2.3. Grouting Device. The grouting tailings reinforcement device under the effect of a seepage field in this experiment includes the seepage part, grouting tube, and peristaltic pump. The device's experiment figure is shown in Figure 2(a). The seepage part is made by polymethyl methacrylate, with the size of $30 \times 15 \times 25 \mathrm{~cm}$; the left and right sides

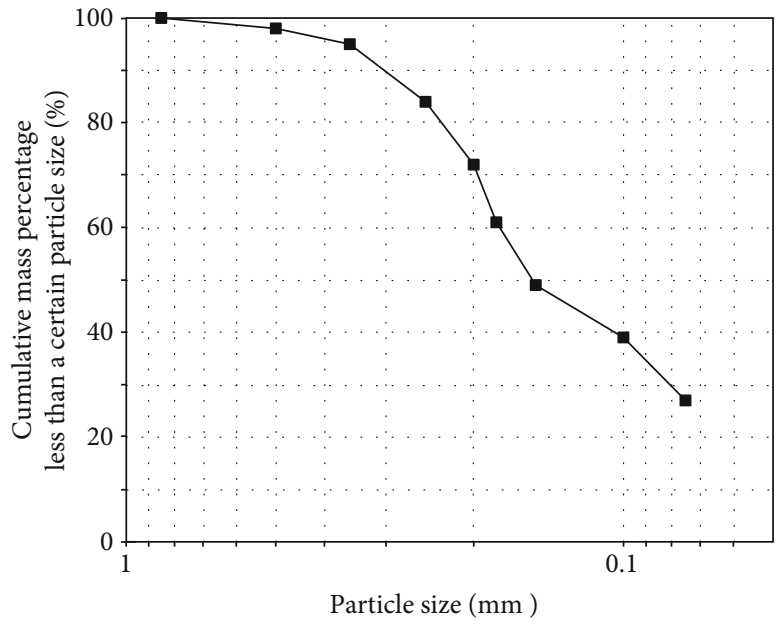

FIgURE 1: Tailings sand grain composition curve.

are two $7 \times 25 \mathrm{~cm}$ water channels. Through altering the difference of water levels in sinks, the hydraulic gradient of a seepage field can be controlled. The constant head permeability is adopted, which changes the difference of water levels in the left and right sink to control the head. The hydraulic gradient of this experiment is set as 1 . There are pores with $2 \mathrm{~mm}$ diameters on the porous disc for water seepage. The diagram of porous disc is shown in Figure 2(b). The grouting tube also uses polymethyl methacrylate, with a pore interval of $1 \mathrm{~cm}$. In order to make a more even grouting and prolong the tube plugging time, the pores adopt the distribution pattern of loose above and dense below [11]. The diagram of the grouting tube is shown in Figure 2(c).

\section{Experiment Method}

3.1. Grouting Experiment. This experiment adopts a comparative experiment as shown in Figure 3. One group is the microbial grouting reinforcement experiment with the effect of a seepage field; the hydraulic gradient is maintained on 1 through controlling the difference of the water level of sinks on both sides. The other group is the microbial grouting reinforcement experiment without the effect of a seepage field; the microbial grouting device of this group is the same as Figure 2(a), but there will be no water in sinks. According to the demands of the geotechnical experiment, the parameters of sands in two groups shall remain the same. A step-bystep grouting method is adopted, which means the bacterial solution will be injected first, then come with the calcium chloride solution (fixing solution), and finally will be the consolidating fluid that mixed with urea and calcium chloride. The time interval for the step-by-step grouting is two hours, while complete grouting takes 4 hours, and grouting consumes a total of 13 days. Each group consumed $3 \mathrm{~L}$ of bacterial solution, $4.3 \mathrm{~L}$ of calcium chloride, and $3 \mathrm{~L}$ of urea.

\subsection{Test Method}

3.2.1. Pore Test. Mercury intrusion methods are a relatively good technology in research porous media. It can intuitively 
TABLE 1: Composition table of a medium for a test.

\begin{tabular}{|c|c|c|}
\hline Culture medium name & $\mathrm{pH}$ & Ingredient \\
\hline $\begin{array}{l}\text { CASO+ urea liquid } \\
\text { medium }\end{array}$ & 7.5 & Casein peptone $15 \mathrm{~g}$, soy peptone $5 \mathrm{~g}, \mathrm{NaCl} 5 \mathrm{~g}$, urea $20 \mathrm{~g}$, nickel chloride $0.0013 \mathrm{~g}$, deionized water $1000 \mathrm{~mL}$ \\
\hline $\begin{array}{l}\text { CASO+ urea solid } \\
\text { medium }\end{array}$ & 7.5 & $\begin{array}{c}\text { Casein peptone } 15 \mathrm{~g} \text {, soy peptone } 5 \mathrm{~g}, \mathrm{NaCl} 5 \mathrm{~g} \text {, urea } 20 \mathrm{~g} \text {, nickel chloride } 0.0013 \mathrm{~g} \text {, agar powder } 20 \mathrm{~g} \text {, } \\
\text { deionized water } 1000 \mathrm{~mL}\end{array}$ \\
\hline
\end{tabular}

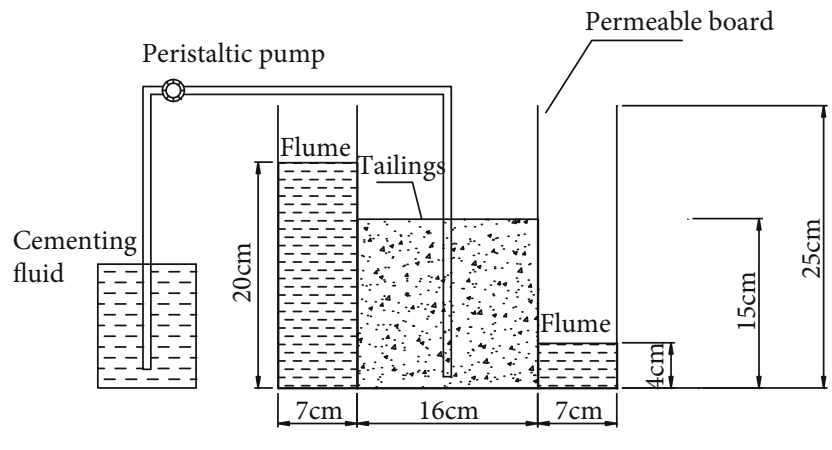

(a)

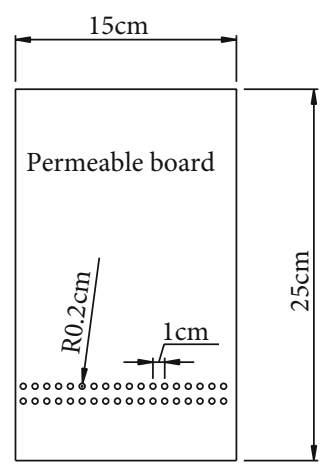

(b)

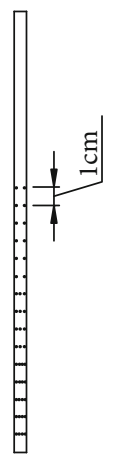

(c)

Figure 2: Diagram of the grouting device.

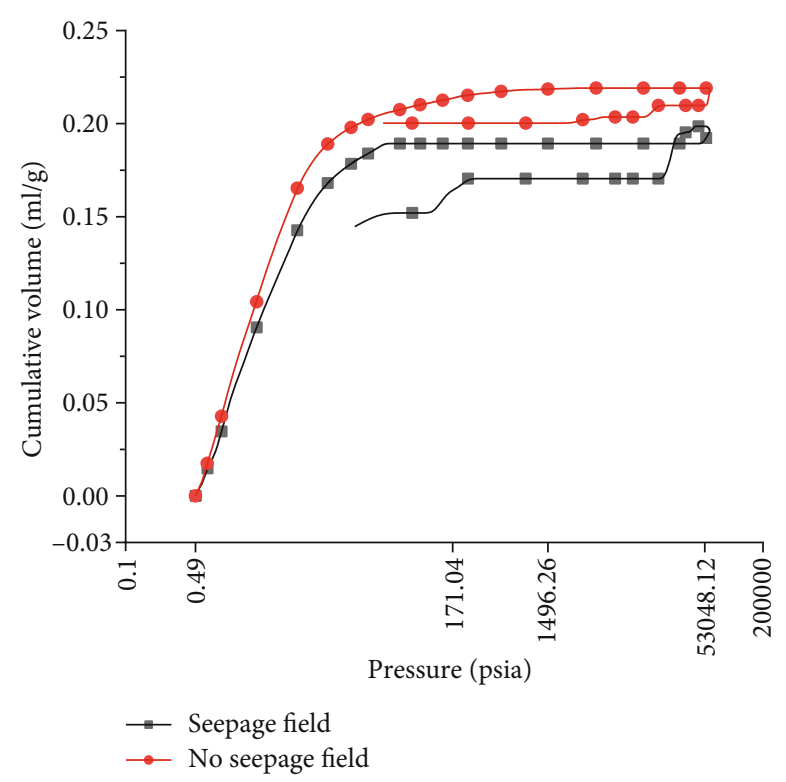

Figure 3: Mercury penetration test curves.

and quantitatively represent the composition and distribution of pores. In this experiment, two sets of tailings samples at the same location were taken after the reinforcement completed, which were further tested by the American Mac Instruments AutoPore IV 9500 automatic mercury intrusion instrument with a contact angle of $130^{\circ}$. After the test, the pore size distribution of the two sets of tailings was compared to analyze the effect of the seepage field on the micropores of the tailings consolidated by microbial grouting.

3.2.2. Scanning Electron Microscope (SEM) Analysis. The scanning electron microscope (SEM) is currently the most direct method in researching the microstructure of geotechnical projects. In the past 20 years, many domestic and foreign scholars have done a lot of qualitative and quantitative researches on the structure of soil, porosity, permeability, fractal dimension, and the orientation and distribution characteristics of soil particles and pores using images obtained by SEM [12]. This experiment uses the FEI-F50 test field SEM (United States), and the tailing sands were taken from the same position of the two groups of experiments that were used for the SEM test to observe the changes in pores.

3.2.3. Shear Strength Indicator Test. This experiment uses a DJS-III Quadruple electric straight shear machine that is manufactured by Nanjing Soil Equipment Factory. Then, three parallel samples with diameters of $61.8 \mathrm{~cm}$ and a height of $20 \mathrm{~mm}$ were taken from the same position of the two groups of reinforced tailings. Such samples will be put in the loading area of the straight shear and load vertical pressure of $50 \mathrm{kPa}, 100 \mathrm{kPa}$, and $150 \mathrm{kPa}$, respectively. The cohesive force $c$ and the internal friction angle $\varphi$ will be compared between the tailings grouting reinforced soil with the effect of the seepage field and without the seepage field.

3.2.4. Calcium Ion Content Determination. After the grouting is finished, the consolidated sand sample will be taken, dried, and put into the beaker. The total mass of the sand sample and the beaker is denoted as $M_{1}$, and the mass of the beaker is denoted as $M_{2}$. Add 1:10 dilute hydrochloric acid to the beaker and soak for $1 \mathrm{~h}$. Wash with distilled water and put it in the oven again to dry. After drying, the total mass of the sand sample and the beaker is denoted as $M_{3}$. The calcium carbonate content $M_{\mathrm{Caco}_{3}}$ is the ratio of the mass of calcium 

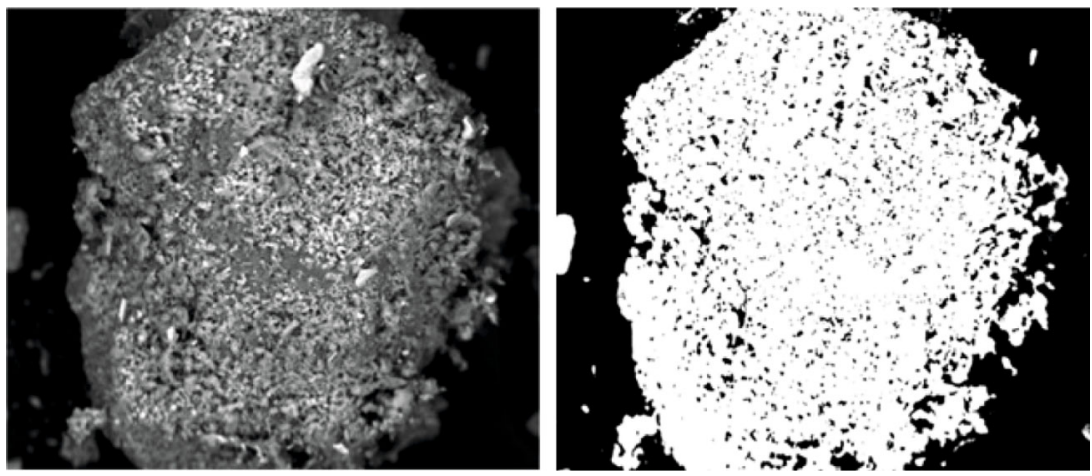

(a) Electron micrograph and pore identification photos after reinforcement without a seepage field
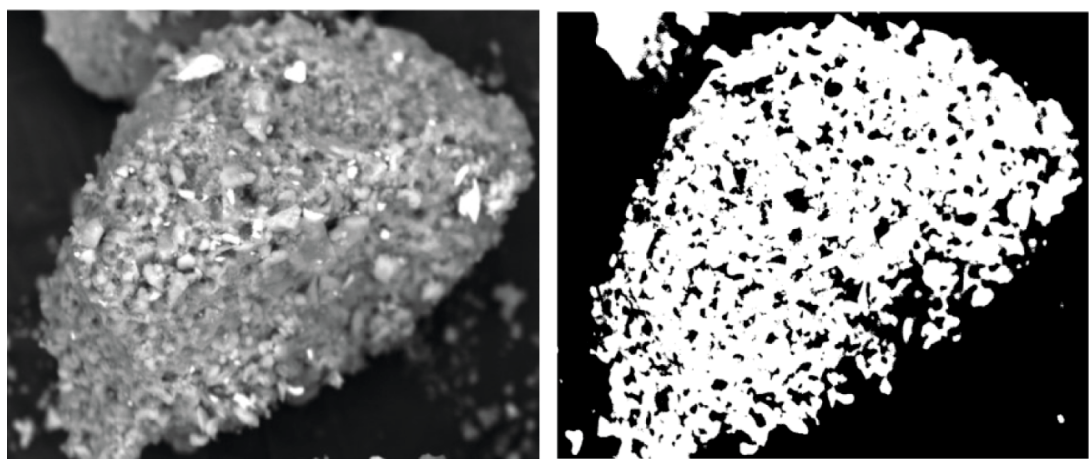

(b) Electron micrograph and pore identification photos after seepage field reinforcement

Figure 4: Scanning electron microscope images and pore identification images.

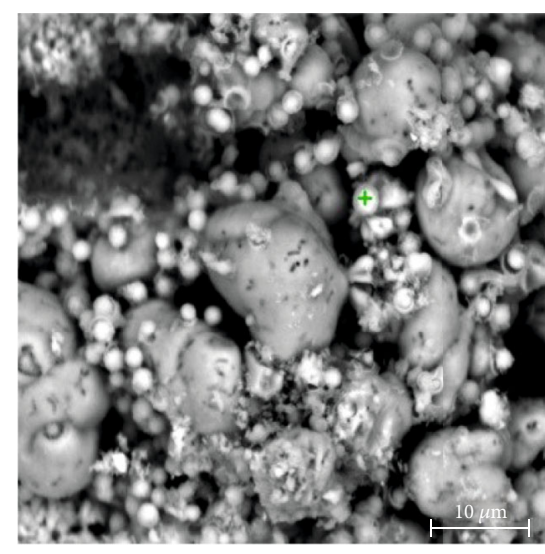

(a) Seepage field effect

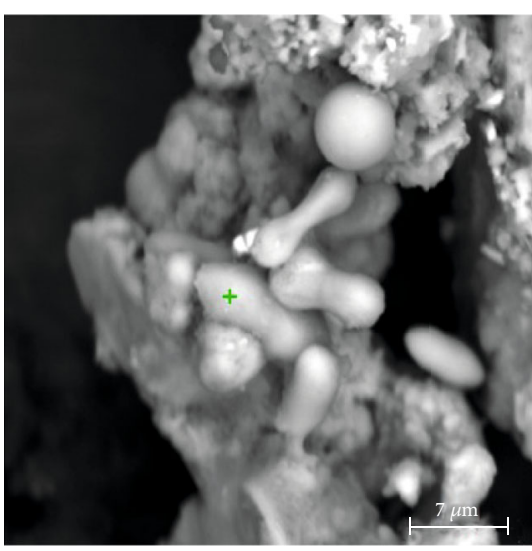

(b) No seepage field effect

Figure 5: Particle bonding images with and without the effect of the seepage field.

carbonate in the sample $\left(M_{1}-M_{2}\right)$ to the total mass of the sample $\left(M_{3}-M_{2}\right)$. The calculation formula is shown in

$$
M_{\mathrm{caco}_{3}}=\frac{M_{1}-M_{2}}{M_{3}-M_{2}} .
$$

\section{Experiment Result Analysis}

4.1. Mercury Penetration Test Analysis. Got the relationship between pressure and the volume of mercury intrusion from the mercury penetration experiment and calculate the pore diameter of the tailing sand sample using the Washbum equation [13] as shown in

$$
R=\frac{-2 \gamma \operatorname{Cos} \theta}{p}
$$

In the equation, $R$ is the pore radius of the tailing sand sample, m. $p$ is the mercury intrusion pressure, $\mathrm{kgf} / \mathrm{cm}^{2}$; the conversion relationship is $1 \mathrm{MPa}=10.197 \mathrm{kgf} / \mathrm{cm}^{2} . \theta$ is the infiltration angle of mercury on the surface of tailing sand, 
which is $130^{\circ}$ in this experiment. $\gamma$ is the surface tension of mercury, which is $0.484 \mathrm{~N} / \mathrm{m}$.

Based on the pore diameter range classification in the Powers-Brunauer model [14] and the conversion relationship between mercury pressure and pore diameter conversion, it divides the mercury penetration curve into large pore segments (0.49 psia 171.04 psia), medium pore segments (171.04 psia 1496.26 psia), and micropore segments (1496.2 psia $\sim 53048.12 \mathrm{psia}$ ). It plots the tailing sand mercury penetration test curves which is with or without the effect of seepage field reinforcing that is shown in Figure 3.

From Figure 3, the effect of the seepage field on the tailing sand pore with microbial grouting reinforcement can be seen. Comparing the mercury intrusion curves in the figure, the microbial grouting reinforcement under the effect of the seepage field results in a smaller total pore diameter. The effect on the large pore segment was the smallest, while the effect on the medium pore and micropore segments was the largest. The curves in the figure overlap at the large pore segment and then gradually separate, indicating that the larger the pore diameter, the smaller the effect of the seepage field. The mercury intrusion curves with the effect of seepage fields were significantly lower than the curves without it in both the medium pore and micropore segments, indicating that seepage fields have a greater effect on the medium pore and micropore segments. The reason for this phenomenon is that the medium particle size and small particle size in the tailing sand sample are transported by the seepage water, leaving the large particle size tailing sand.

In the figure, the mercury extrusion curve is located below the mercury intrusion curve, indicating that the sample locally crumbled during the depressurization process and the proportion of large pores increases, which caused the pore diameter distribution to be inconsistent with that of mercury intrusion.

4.2. SEM Experimental Analysis. Import the images of the sample with the effect seepage field reinforcement, which is magnified 1600 times under the scanning electron microscope, and the images of the sample without it have the same magnification into the PCAS pore identification software. In order to minimize the effect of the sample surface's calcium carbonate on the pore identification, it referred to literature $[15,16]$ to set thresholds so that the sand part is white, and the pore part is black. As shown in Figure 4, (a) is the scanning electron microscope image without the effect of seepage field reinforcement and the image after identification of the pore and (b) is the scanning electron microscope image with the effect of seepage field reinforcement and the image after identification of the pore. It can be visually observed from the figure that large pores with the effect of seepage field reinforcement are significantly more than without, which is consistent with the situation of local pore size enlargement due to the transport of loose particles by seepage water as proposed by Yin et al. [17].

The particle bonding with and without the effect of seepage field reinforcement can be seen in Figure 5. From Figure 5(a), the particles without the effect of seepage field reinforcement are surrounded by multiple spherical cal-

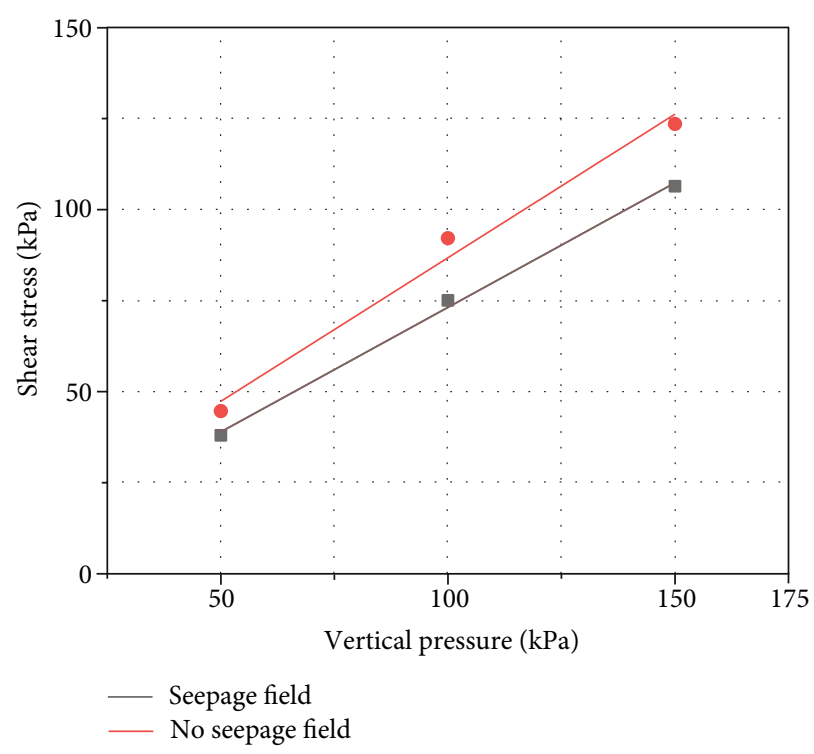

FIGURE 6: Shear experiment images.

cium carbonate crystals, mostly vaterite. While from Figure 5(b), the amount of bonding calcium carbonate between particles with the effect of seepage field reinforcement is less. This is due to the effect of seepage; the bacteria solution and bonding fluid are difficult to fix in the tailing sand, which in turn leads to the amount of calcium carbonate that becomes less.

4.3. Shear Strength Index Analysis. Take 3 duplicate samples of $61.8 \mathrm{~mm}$ diameter and $20 \mathrm{~mm}$ height from the same part of two samples with reinforcement, and place them in the loading area of direct shear apparatus, then, respectively, apply vertical pressures of $50 \mathrm{kPa}, 100 \mathrm{kPa}$, and $150 \mathrm{kPa}$, to get the shear images as shown in Figure 6.

Finally, it is concluded that the cohesive force after reinforcement with the effect of seepage field reinforcement is 3.8 and the internal friction angle is $34.4^{\circ}$, while the cohesion force without the effect of seepage field reinforcement is 5.15 and the internal friction angle is $37.9^{\circ}$. The shear strength without the effect of seepage grouting reinforcement is significantly greater than the shear strength with the effect of seepage reinforcement. This is because under the effect of seepage, the amount of the bacteria solution and bonding fluid fixed in the sandy soil decreases, which in turn leads to a decrease of crystallization points, which ultimately leads to a decrease in the amount of calcium carbonate crystals and a decrease of cohesion.

Analyzing from the microperspective, through the mathematical model proposed by Cheng et al. [18], it assumes that the sand particles are uniformly spherical particles and the generated calcium carbonate precipitate is uniformly attached around the particles, as shown in Figure $7(\mathrm{a})$. As shown in Figure $7(\mathrm{~b})$, the generated point-to-point crystal hinges between particles can effectively increase the bonding force between particles, and the larger the generated hinge volume, the stronger the bonding force. 


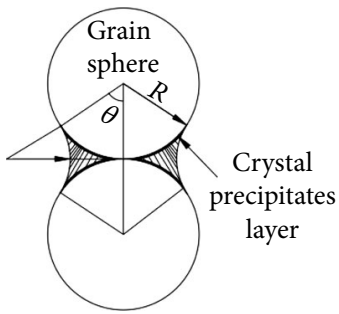

(a)

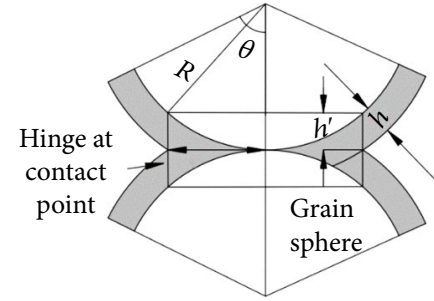

(b)

Figure 7: Particle bonding images.

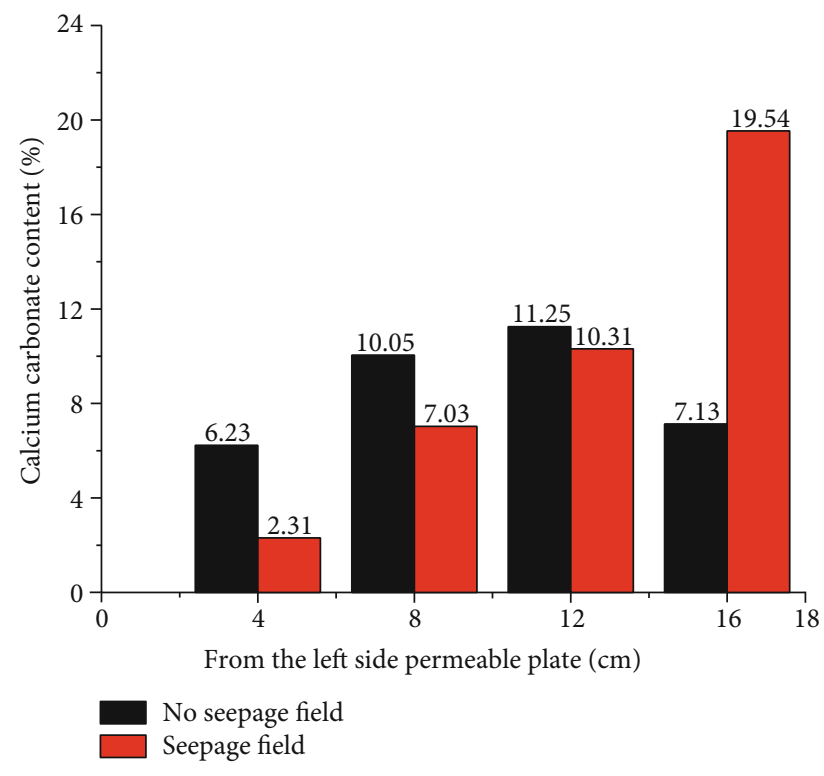

Figure 8: Calcium ion content of each part.

In sandy soils, based on the shown geometrical relationship, the total volume of the hinge can be calculated according to the following equation:

$$
V_{T \text {-hinges }}=\frac{6 v\left[2 \pi r^{2} h^{\prime}-(2 \pi / 3) h^{\prime 2}\left(3 r-h^{\prime}\right)\right]}{5.66 R^{3}} .
$$

In the equation, $V_{T \text {-hinges }}$ is the total volume of the hinge, $v$ is the porosity, $R$ is the particle radius, and $h^{\prime}$ is shown in Figure 7(b).

From the above equation, the particle radius is inversely proportional to the total hinge volume, the larger the particle, the smaller the hinge volume, and the weaker the bonding force between the particles. Grouting with the effect of a seepage field, the seepage force will transport the small particles, leaving large particles, which causes the hinge volume between the particles to become smaller and the bonding force to reduce. While grouting without the effect of a seepage field, small particles are more, and the generated hinge volume is large. Therefore, the shear strength with the effect of seepage field microbial grouting reinforcement is less than the shear strength without the effect of a seepage field.
4.4. Determination of Calcium Ion Content. The two groups of reinforced samples are divided into four parts from left to right with the same size. Their distance to the porous disc shown in Figure 1 is $4 \mathrm{~cm}, 8 \mathrm{~cm}, 12 \mathrm{~cm}$, and $16 \mathrm{~cm}$, respectively. The calcium content of each part is tested as shown in Figure 8.

Through Figure 8, it can be concluded that for the sample with the seepage effect, the calcium ion content increases with the distance to the porous disc on the left. That is because, with the transferring of calcium ion to the direction of seepage, the calcium ion will accumulate on the right porous disc, thereby causing a high concentration near the right porous disc. Since the grouting tube is in the middle of the device, which is the most remote from the left grouting tube, the action of seepage and the infiltration capacity of the bacterial solution and the consolidating fluid are decreased, causing the lowest content of calcium carbonate on the left. For the samples with the action of the seepage field, the relationship between the transferring routine of calcium ions and the hydraulic gradient of the seepage field requires further experimental verification. For the samples without the action of the seepage field, the further distance to the grouting tube, the less content of calcium carbonate generated. The content of calcium ion in the sample without the action of the seepage field decreases with the increasing distance to the grouting tube due to the percolation effect [19].

Cheng et al. [18] discovered that, for the samples with lower saturation, the content of calcium carbonate generated will be higher. Due to the existence of the seepage field, the saturation of the sample is relative, which further causes a relatively low content of calcium carbonate.

\section{Conclusion}

(1) With the effect of the seepage filed, the microbial grouting reinforcement will decrease the total pore diameter of tailings. And the seepage field's impact on the quantity of the macropore section is lower than the quantity of the micropore section. Since small particles are transferred by the seepage water, the regional pore diameters are enlarged

(2) Under the action of the seepage field, the cohesive force of the microbial grouting reinforced sample is reduced by $27 \%$, and the internal friction angle decreased 
(3) The gemel volume that formed between particles is reversely proportional to the size of particles $R$, while the existence of the seepage field will cause a decrease in the quantity of small particles and the volume of gemel. Therefore, the microbial grouting reinforcement with the action of the seepage field is lower than those without the action of the seepage field

(4) The calcium ion will transfer with the seepage field, causing an uneven distribution of calcium ion. And under the action of the seepage field, the amount of calcium carbonate generated will decrease

\section{Data Availability}

Basic research data can be obtained from the corresponding author.

\section{Conflicts of Interest}

The authors declare no conflicts of interest.

\section{Acknowledgments}

This study was supported by the National Natural Science Foundation of China (51804164, 51774187, and 51974163), the Natural Science Foundation of Hunan Province (2019JJ50498 and 2017JJ3274), and the Scientific Research Foundation of Hunan Provincial Education Department (18B276 and 17A184). The authors would like to thank the Hunan Province \& Hengyang City Engineering Technology Research Center for Disaster Prediction and Control on Mining Geotechnical Engineering (2019TP2070) for providing experimental platform support.

\section{References}

[1] Y. X. Wang and Z. K. Mi, "Safety risk analysis and evaluation method for tailings dam break," Metal Mine, vol. 6, pp. 184188, 2019.

[2] V. S. Whiffin, L. A. Van Paassen, and M. P. Harkes, "Microbial carbonate precipitation as a soil improvement technique," Geomicrobiology Journal, vol. 24, no. 5, pp. 417-423, 2007.

[3] J. T. Dejong, M. B. Fritzges, and K. N. U. Sslein, "Microbially induced cementation to control sand response to undrained shear," Journal of Geotechnical and Geoenvironmental Engineering, vol. 132, no. 11, pp. 1381-1392, 2006.

[4] N. Hamdan, E. Kavazanjian, B. E. Rittmann, and I. Karatas, "Carbonate mineral precipitation for soil improvement through microbial denitrification," Geomicrobiology Journal, vol. 34, no. 2, pp. 139-146, 2017.

[5] L. A. van Paassen, R. Ghose, T. J. van der Linden, W. R. van der Star, and M. C. van Loosdrecht, "Quantifying biomediated ground improvement by ureolysis: large-scale biogrout experiment," Journal of Geotechnical and Geoenvironmental Engineering, vol. 136, no. 12, pp. 1721-1728, 2010.

[6] L. A. van Paassen, Bio-mediated ground improvement:from laboratory experiment to pilot applications. Geo-Frontiers: Advances in Geotechnical Engineering, ASCE, Dallas, 2011.
[7] C. X. Qian, A. H. Wang, and X. Wang, "Advances of soil improvement with bio-grouting," Rock and Soil Mechanics, vol. 36 , no. 6, pp. 1537-1548, 2015.

[8] H. Y. Xu, J. J. Lian, and Y. Yan, "Experimental study of MICP solidified sand under the coupling of multiple test factors," Journal of Tianjin University(Science and Technology), vol. 53, no. 5, pp. 517-526, 2020.

[9] S. Liu, J. Yu, X. Peng, Y. Cai, and B. Tu, "Preliminary study on repairing tabia cracks by using microbially induced carbonate precipitation," Construction and Building Materials, vol. 248, p. 118611, 2020.

[10] V. R. Karnati, T. Munaga, K. K. Gonavaram, and B. Amitava, "Study on strength and leaching behavior of biogeochemical cemented sand," Geomicrobiology Journal, vol. 37, no. 7, pp. 670-681, 2020.

[11] J. Peng, M. F. Huang, G. Q. Xie, and Y. M. Tian, "Grouting method of MICP-treated soil," Journal of Hohai University(Natural Sciences), vol. 47, no. 3, pp. 259-264, 2019.

[12] C. S. Tang, B. Shi, and B. J. Wang, "Factors affecting analysis of soil microstructure using SEM," Chinese Journal of Geotechnical Engineering, vol. 4, pp. 560-565, 2008.

[13] J. Lee and J. Shang, "Micropore structure of cement-stabilized gold mine tailings," Minerals, vol. 8, no. 3, p. 96, 2018.

[14] C. Liu, B. Shi, J. Zhou, and C. S. Tang, "Quantification and characterization of microporosity by image processing, geometric measurement and statistical methods: application on SEM images of clay materials," Applied Clay Science, vol. 54, no. 1, pp. 97-106, 2011.

[15] P. Nattaporn, S. Anchalee, K. Irb, and J. G. Robert, "SEM image analysis for characterization of sand grains in Thai paddy soils," Geoderma, vol. 156, no. 1-2, pp. 20-31, 2010

[16] V. N. Sokolov, D. I. Yurkovets, O. V. Ragulina, and V. N. Melnik, "Computer-controlled system for the study of micromorphology of the surface of solids by SEM images," Surface Investigation, vol. 14, pp. 33-41, 1998.

[17] G. Yin, Q. Zhang, W. Wang, Y. Chen, W. Geng, and H. Liu, "Experimental study on the mechanism effect of seepage on microstructure of tailings," Safety Science, vol. 50, no. 4, pp. 792-796, 2012.

[18] L. Cheng, R. Cord-Ruwisch, and M. A. Shahin, "Cementation of sand soil by microbially induced calcite precipitation at various degrees of saturation," Canadian Geotechnical Journal, vol. 50, no. 1, pp. 81-90, 2013.

[19] X. F. Chong, F. G. Wang, and B. Zhang, "The variation of granular slurry diffusion distance in sand medium [J/OL]," Journal of Shandong University(Engineering Science), vol. 2020, pp. 16, 2020. 